\title{
Effects of Aloe vera Cream On Skin Wound Healing In Sprague Dawley Rats: The Role of $\mathrm{CD} 4^{+}$And $\mathrm{CD} 8^{+}$Lymphocytes
}

\author{
Yos Adi Prakoso ${ }^{1, a^{*}}$ and Kurniasih ${ }^{2, \text { b) }}$ \\ ${ }^{1}$ Graduate Student, Faculty of Veterinary Medicine, Gadjah Mada University, Indonesia \\ ${ }^{2}$ Department of Pathology, Faculty of Veterinary Medicine, Gadjah Mada University, Indonesia

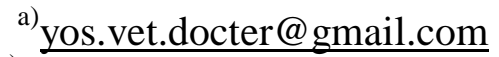 \\ b) kurniasih_1951@yahoo.co.id
}

\begin{abstract}
Wound is defined as a damage of the normal anatomical structure and function of tissues. Aloe verais one of potential herbal on wound healing. The aim of this study is to explore the effect of topical Aloe vera on skin wound healing in Sprague Dawley rats. Thirty six male Sprague Dawley rats 150-200 grams were divided into four groups. All groups were anaesthetised, shaved, and exposed two round full-thickness punch biopsy on the back. Group I as control group; group II treated with topical application of Aloe vera cream 1\%; group III treated with topical application of Aloe vera cream 2\%; and group IV treated with topical application of madecassol ${ }^{\circledR}$. The treatments were given once a day, for 15 days. Macroscopic and microscopic examination were observed at 5,10 and 15 days post skin biopsy. Skin specimens were prepared for histopatological study using Hematoxillin and Eosin (HE) and immunohistochemistry (IHC) staining. HE were used to analysed epidermal thickness, leucocytes infiltration, fibroblast, and angiogenesis. IHC using antibody anti-CD $4^{+}$and $\mathrm{CD}^{+}$were used to analysed the expression of $\mathrm{CD}^{+}$and $\mathrm{CD}^{+}$lymphocytes. All the microscopical data collection were performed by ImageJ software, and then all data were analysed by Statistical Package for the Social Sciences 16(SPSS.16). Result of this research shows that topical application of Aloe vera cream $1 \%$ and $2 \%$ significantly reduced the percentage of wound, leucocytes infiltration, angiogenesis, expression of $\mathrm{CD}^{+}$lymphocytes. However, epidermal thickness and the expression of $\mathrm{CD} 4^{+}$ lymphocytes increased $(\mathrm{p} \leq 0,05)$. There were no significant different in the number of fibroblast in all groups. Topical application of Aloe vera $1 \%$ and $2 \%$ have wound healing potential via its ability to increase the ratio of $\mathrm{CD} 4^{+} / \mathrm{CD}^{+}$lymphocytes in the wound area.
\end{abstract}

Keywords: Aloe vera, cream, wound healing, $C D 4^{+}$and $C D 8^{+}$lymphocytes

\section{INTRODUCTION}

Aloe vera is the one of potential herbal and could be found in tropical area [1], such as Indonesia. Inside the Aloe vera leaf contains gel [2]. It gel contains flavonoid, terpenoid, lectin, anthraquinone, tannin and saponin. And these contents have pharmacological properties to promote wound [3], skin burn [4], anti-bacterial [5], anti-inflammatory [6], cosmetic, moisturizer and could used as dermatological products [7].

Damage of the normal anatomical structure and function of tissues difened as wound [8]. In a normal, each wound will be healed through the process involve hemostasis, inflammation, proliferation, maturation and remodeling [8-9]. T lymphocytes, especially $\mathrm{CD}^{+}$plays the important role in wound healing by secreted lymphokines to activate fibroblast, as wound antiinflammatory agent and activate factor in major histocompatibility complex(MHC) class II. On the other hand, $\mathrm{CD}^{+}$lymphocytes plays as pro-inflammatory and activate factor in MHC class I [10]. 
Effect of Aloe vera on wound healing, especially role of $\mathrm{CD}^{+}$and $\mathrm{CD} 8^{+}$lymphocytes are not fully known. In this study, effect of Aloe vera on percentage of wound area, epidermal thickness, neutrophil infiltration, fibroblast, angiogenesis, $\mathrm{CD} 4^{+}$and $\mathrm{CD} 8^{+}$lymphocytes were observed.

\section{MATERIAL AND METHODS}

All animal procedure in this study were approved by ethical clearance committee of Gadjah Mada University, with licence numbers: 00052/04/LPPT/VII /2016. Aloe vera from Kalimantan, Indonesia were used in this study. Aloe vera leafs were peeled, cut, put in a blender mix and extracted by alcohol $70 \%$. Aloe vera extract was made into cream $1 \%$ and $2 \%$ concentration. Cream were made from mixtured of Aloe verae xtract, stearic acid, potassium hydroxide $(\mathrm{KOH})$, glycerin, methyl paraben, propyl paraben, and water [11].

Thirty six male Sprague Dawley rats weighing 150-200 grams were divided into four groups. All groups were shaved, and exposed two round $4 \mathrm{~mm}$ full-thickness punch biopsy on the back under ketamine $50 \mathrm{mg} / \mathrm{kg} \mathrm{BW}$ and xylazine $4 \mathrm{mg} / \mathrm{kg}$ BW anasthesia. Next, group I as control group; group II treated with topical application of Aloe vera cream 1\%; group III treated with Aloe veracream $2 \%$; and group IV treated with madecassol ${ }^{\circledR}$. The treatments were given once a day, for fifteen days. Three rats from each group were euthanasia with cervical dislocation on day 5, 10 and 15 to collected skin specimen. The collected specimen was stored in neutral buffer formalin $10 \%$ for histopathological examination with HE and IHC stain. IHC stain used monoclonal antibodies for $\mathrm{CD}^{+}$(anti rat CD4 ${ }^{+}$, Novocastra, RTU-CD4-1F6,Cat. No. PA0427) and $\mathrm{CD}^{+}$(anti rat $\mathrm{CD}^{+}$, Novocastra, RTU-CD8-295,Cat. No. PA0183).

The data was divided into macroscopical and microscopical data. Macroscopical data was percentage of wound area. Microscopical data was epidermal thickness, neutrophils infiltration, fibroblast, angiogenses, $\mathrm{CD}^{+}$and $\mathrm{CD}^{+}$lumphocytes. Microscopical examination performed by ImageJ software. All data were analysed by SPSS 16. Epidermal thickness, neutrophils infiltration, fibroblast, angiogenesis and $\mathrm{CD} 8^{+}$lymphocytes data were analysed with Kruskal-Wallis and MannWhitney U Test. CD4 ${ }^{+}$lymphocytes was analysed with Two Way Anova and Post Hoc Test.

\section{RESULT AND DISCUSSION}

There is significantly difference between group II, group III and group IV compared with group I $(p \leq 0,05)$. It show that topical application of Aloe veracream $1 \%, 2 \%$ and madecassol® has potential effect on wound healing to the percentage of wounds area (FIGURE 1a and FIGURE 1b). All groups showed that epidermal thickness increased, however neutrophils infiltration and angiogenesis decreased as the day of wound healing process. Group II and group III showed significantly epidermal thickness increasing $(\mathrm{p} \leq 0,05)$ (FIGURE 2a) and neutrophils infiltration decreasing $(\mathrm{p} \leq 0,05)$ (FIGURE $2 \mathbf{b})$, as well as angiogenesis compared with the other group $(\mathrm{p} \leq$ 0,05) (FIGURE 3a). Proliferating of fibroblast didn't show significantly difference in all groups ( $p$ $\geq 0,05)$. Fibroblast increased significantly as the day through wound healing process $(\mathrm{p} \leq 0,05)$ (FIGURE 3b). These result shows that Aloe vera cream $1 \%$ and $2 \%$ has better effect than madecassol® against the epidermal thickness, neutrophil infiltration and angiogenesis, however not on fibroblast. 


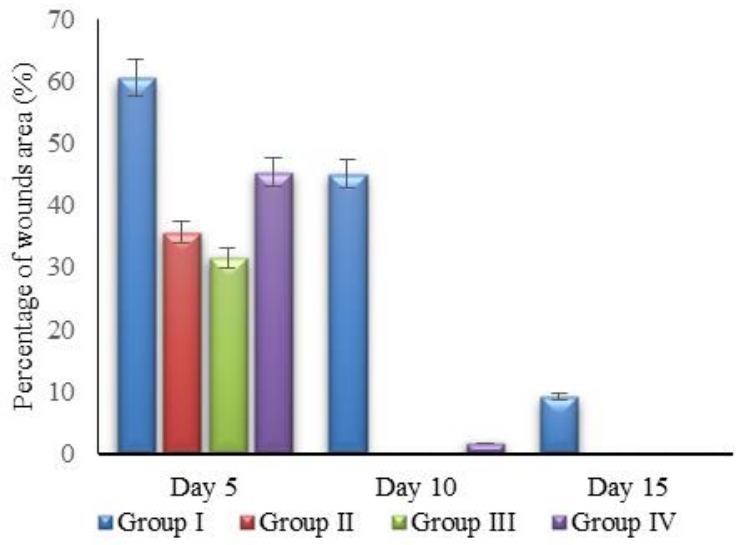

(a)

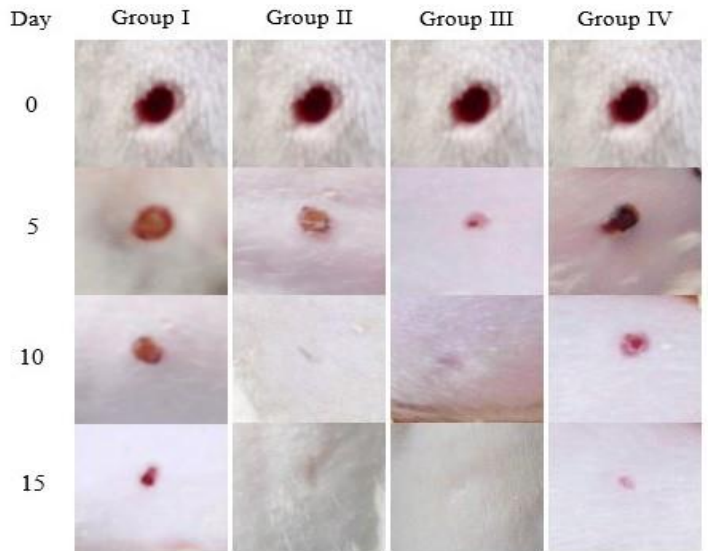

(b)

FIGURE 1. Percentage of wounds area (a);macroscopical examination of wound area from each group (b).

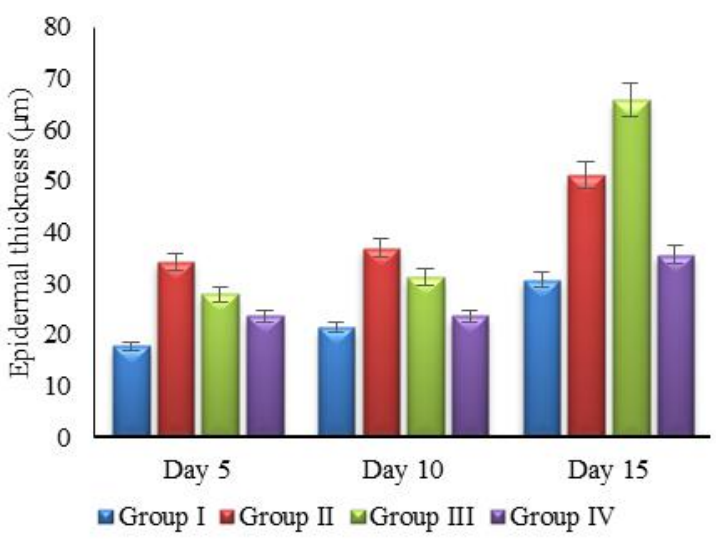

(a)

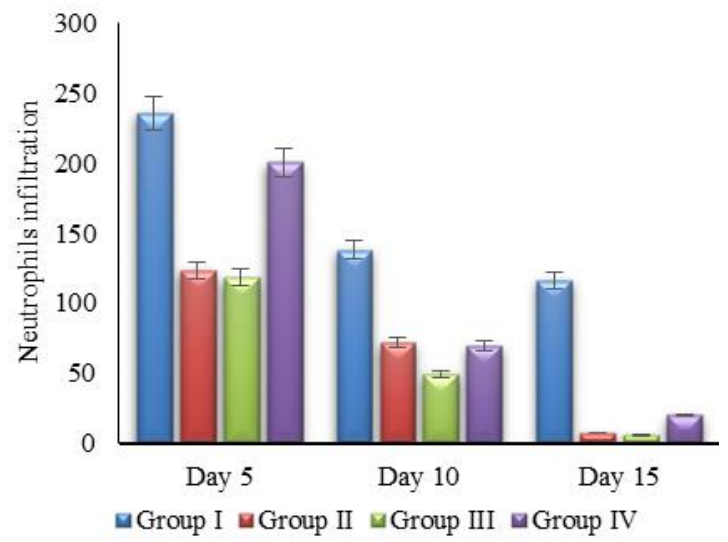

(b)

FIGURE 2. The average thickness of epidermis (a); the average number of neutrophils infiltration (b) on skin wound.

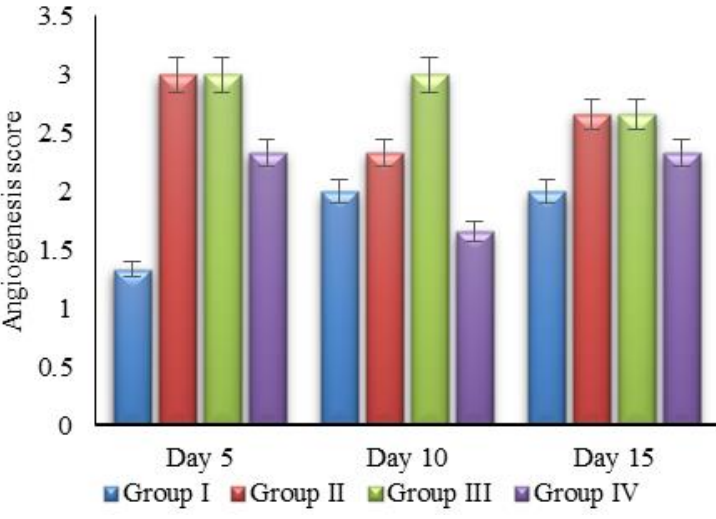

(a)

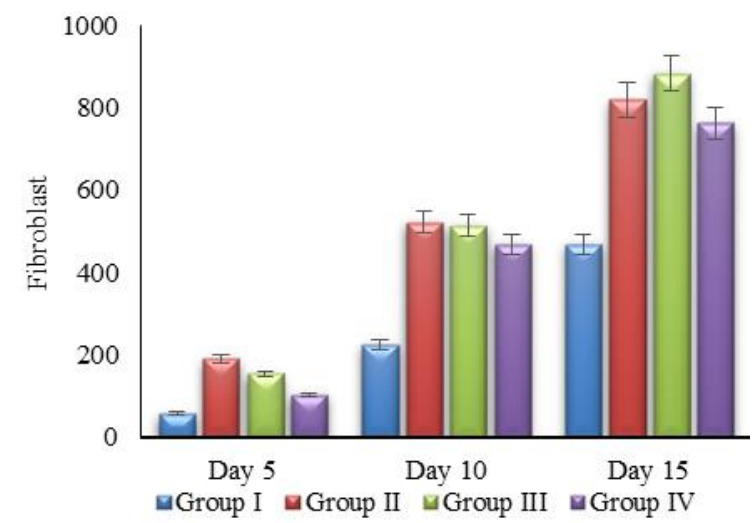

(b)

FIGURE 3. The average score of angiogenesis (a); the average number of fibroblast (b) on skin wound.

$\mathrm{CD} 4^{+}$lymphocytes in this study showed there is no difference between all groups $(\mathrm{p} \geq 0,05)$, although $\mathrm{CD}^{+}$lymphocytes in group II and group III increased maximally on day 5 compared with other groups. $\mathrm{CD}^{+}$lymphocytes in group I increased on day 10 , while the other groups decreased (FIGURE 4). Based on this study, increasing of $\mathrm{CD}^{+}$lymphocytes in group I slower than the other which impaire wound healing. $\mathrm{CD} 8^{+}$lymphocytes infiltration in group I and group IV higher than group II and group III (FIGURE 5). Decreasing of $\mathrm{CD}^{+}$lymphocytes followed by decreasing of $\mathrm{CD}^{+}$lymphocytes $(\mathrm{p} \leq 0,05)$. These study showed that Aloe vera may shorten healing period by increasing $\mathrm{CD}^{+} / \mathrm{CD}^{+}$lymphocytes infiltration ratio earlier on wound tissue. 


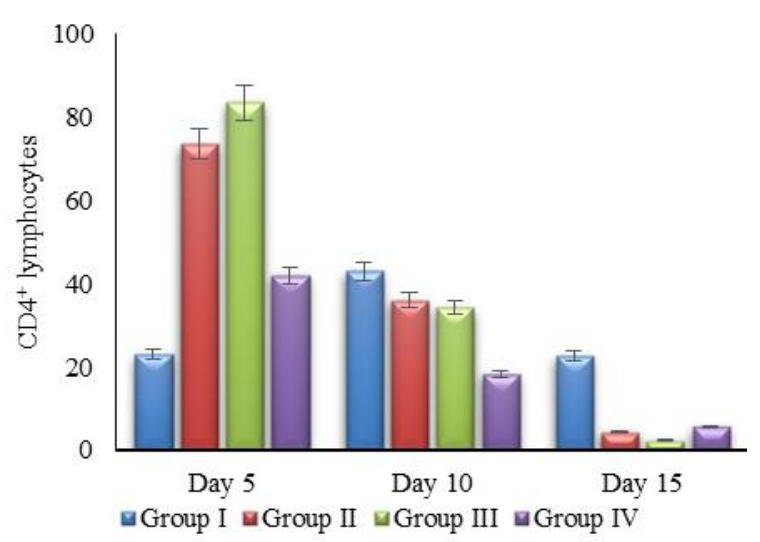

(a)

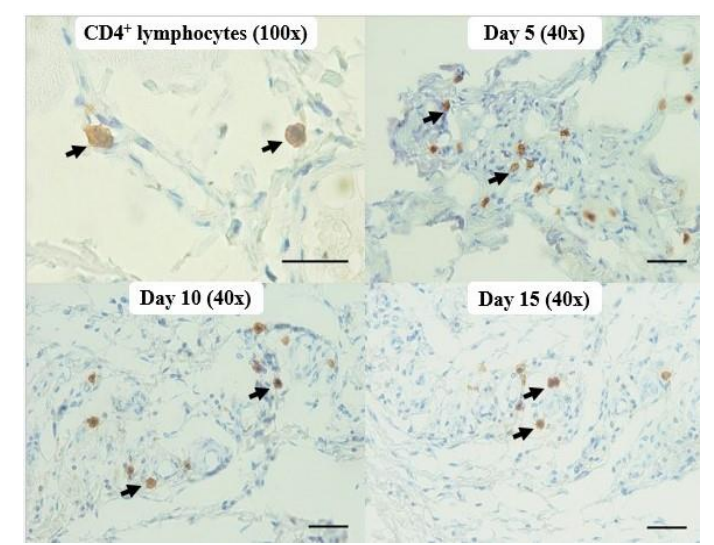

(b)

FIGURE 4. The average number of $\mathrm{CD}^{+}$lymphocytes (a); microscopical examination of $\mathrm{CD} 4^{+}$ lymphocytes on skin wound (IHC antibody anti $\mathrm{CD} 4^{+}, \mathrm{DAB}$, scale bar $50 \mu \mathrm{m}$ ).

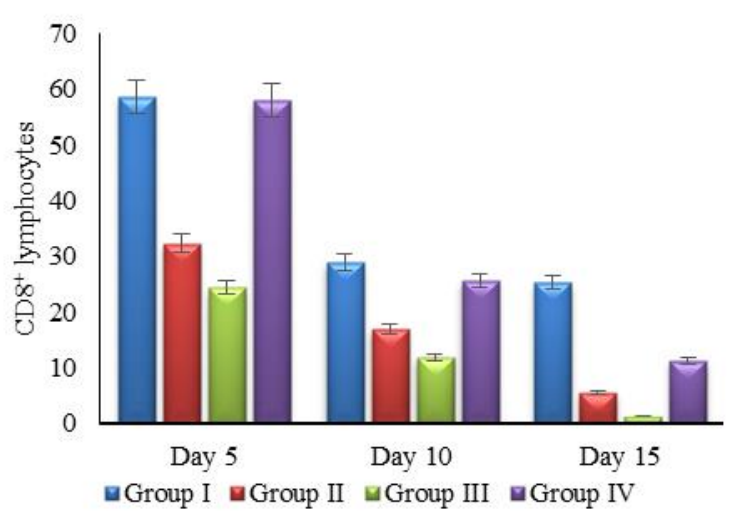

(a)

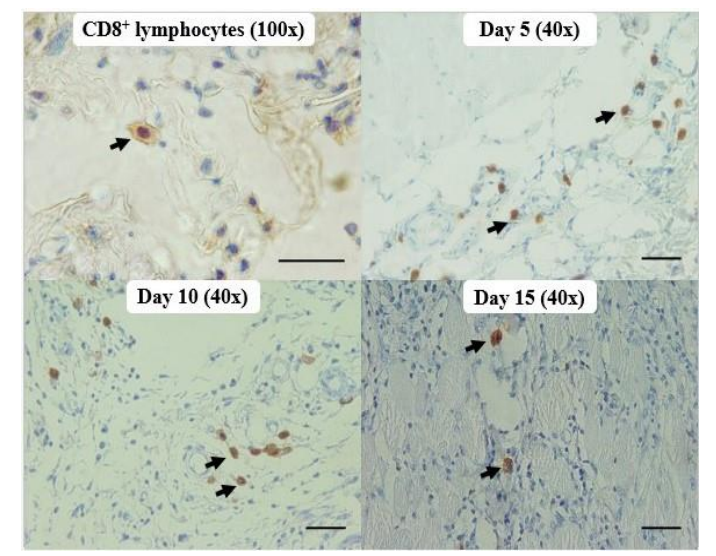

(b)

FIGURE 5. The average number of $\mathrm{CD}^{+}$lymphocytes (a); microscopical examination of $\mathrm{CD} 8^{+}$ lymphocytes on skin wound (IHC antibody anti $\mathrm{CD}^{+}, \mathrm{DAB}$, scale bar $50 \mu \mathrm{m}$ ).

Aloe vera contains anthraquinone, sterol and saponin. That active ingredients have a role as antibacterial and wound healing promotor [12]. Topical application of Aloe vera cream increase the number of $\mathrm{CD}^{+}$lymphocytes and decrease $\mathrm{CD}^{+}$lymphocytes. Increasing the number of $\mathrm{CD}^{+} / \mathrm{CD}^{+}$lymphocytes ratio in group II and group III induces the other healing factors to promote wound [13]. Aloe vera application on wound have a potential effect as anti-inflamatory agent. Its ability decrease leucocytes adhesion on wound via cyclooxygenase and prostaglandin route [14]. Inflammatory brief period during wound will make faster healing process to the next phase. On proliferation phase, $\mathrm{CD}^{+}$lymphocytes induces keratinocytes to release IL- 1 in wound area. Keratinocytes has a potential role on epithelisation, proliferation and maturation of epidermis [15]. IL-1 that has been released by keratinocytes induces endothelial cells to form angiogenesis and fibroblast to form extracellular matrix [16].

Angiogenesis was formed to supply nutrition and others healing factors to wound area [17]. Failure of angiogenesis impaire wound healing [18]. In this study, increasing number of $\mathrm{CD}^{+} / \mathrm{CD}^{+}$lymphocytes ratio in group II and group III activate angiogenesis maximally on day 5 and it makes healing faster. Angiogenesis mediates fibroblast migration on wound tissues. Fibroblast-like cells appeared in group II and group III on day 5. Fibroblast-like cells is one indicator that healing process occurred faster [19]. It proves that Aloe vera has a potential effect on healing. Increasing of fibroblast as a result of lymphokine induced which secreted by CD4 ${ }^{+}$ lymphocytes [20]. $\mathrm{CD}^{+}$lymphocytes have a role as healing promotor to cellular imunrespon [21]. 
$\mathrm{CD}^{+}$lymphocytes depletion can decrease skin tension and extracellular matrix component [22]. On the other hand, $\mathrm{CD}^{+}$lymphocytes have a role as pro-inflammatory agent [23] and as pain receptor. Increasing of $\mathrm{CD}^{+}$lymphocytes impaired wound healing. In this study, decreasing of $\mathrm{CD}^{+}$lymphocytes on wound area followed by increasing of $\mathrm{CD} 4^{+}$lymphocytes. Decreasing of $\mathrm{CD}^{+}$lymphocytes on wound area can decrease IL-3, so that healing process faster [24]. Healing process could be identified macroscopically by percentage of wound area (FIGURE 1b).

\section{CONCLUSION}

Aloe vera has a potential effect to decrease $\mathrm{CD} 8^{+}$lymphocytes and increase $\mathrm{CD} 4^{+}$lymphocytes. That's mechanism influence on wound healing by decrease percentage of wound area, neutrophils infiltration and angiogenesis, however increase epidermal thickness and fibroblast in wound tissue. Aloe vera cream $1 \%$ and $2 \%$ have similar potential effect and both of Aloe vera cream $1 \%$ and $2 \%$ can be used as alternative therapy on wound.

\section{REFERENCES}

[1] Rodriguez-Rodriguez E, Darias Martin J, Diaz Romero C, 2010, Crit Rev Food SciNutr, 50, 305-26.

[2] Kammoun M, Miladi S, Ali YB, Damak M, Gargouri Y, Bezzine S, 2011, Lipids in Health and Disease, 10 (30), 1-7.

[3] Sahu PK, Giri DD, Singh R, Pandey P, Gupta S, Shrivastava AK, Kumar A, Pandey KD, 2013, Pharmacology and Pharmacy, 4, 599-610.

[4] Ahmed AM, Hamid A, Soliman MFM, 2015, J HistoHistopathol, 2 (3), 1-9.

[5] Adnan MJ, Al-Ahbabi HH, Alhussani R, Hamad A, 2015, IJAR, 3, 593-601.

[6] Langmead L, Feakins RM, Goldthorpe S, Holt H, Tsironi E, De Silva A, Jewell DP, Rampton DS, 2004, Alimentary Pharmacology and Therapeutics, 19, 739-747.

[7] Kumar KPS, Bhowmik D, Chiranjib, Biswajit, 2010, J Chem Pharm Res, 2 (1), 21-29.

[8] Velnar T, Bailey T, Smrkolj V, 2009, The Journal of International Reseacrh, 37, 1528-1542.

[9] Rodero MP, Khosrotehrani K, 2010, Int J ExpPathol, 3 (7), 543-653.

[10] Korelo, R.I.G., Kryczyk, M., Garcia, C., Naliwaiko, K., and Fernandes, L.C, 2015, Braz.J.Phys.Ther, 20 (2), 133-141.

[11] Pereira, A. and Mallya, R, 2015, JPP, 4 (2), 232-240.

[12] Ariyanti, N.K., Darmayasa, I.B.G., and Sudirga, S.K, 2012, JurnalBiologi, Vol XVI, 1: 1-4.

[13] Havran, W.L. and Jameson, J.M, 2010, J. Immunol, 184, 5423-5428.

[14] Mukherjee, P.K., Nema, N.K., Bhadra, S., Mukherjee, D., Braga, F.C., and Matsabisa, M.G, 2014, Indian J Traditional Knowledge, 13 (2), 235-256.

[15] Lugo, L.M., Lei, P., and Andreadis, S.T, 2011, Tissue Engineering: Part A, 17 (5), 665-675.

[16] Marmaras, A., Lendenmann, T., Civenni, G., Franco, D., Poulikakos, D., Kurtcuoglu, V., and Ferrari, A, 2012, The Royal Society of Chemistry, 8, 2922-2930.

[17] Tonnesen, M.G., Feng, X., and Clark, R.A.F, 2000, JID Symposium Proceddings, 5, 40-46.

[18] Johnson, K.E., and Wilgus, T.A, 2014, Advance in Wound Care, 3 (10), 647-661.

[19] McDougall, S., Dallon, J., Sherratt, J., and Maini, P, 2006, Phil.Trans.R.Soc.A, 368, 13851405.

[20] Baum, C.L. and Arpey, C.J, 2005, DermatolSurg, 31, 674-686.

[21] Flohe, S., Flohe, S.B., Schade, F.U., and Waydhas, C, 2007, Langenback Arch Surg, 392, 639-648.

[22] Ergun, S.S., Kiran, B., Su, O., Bilgic, B., Yssever, H., and Kucuk, M, 2004, Ann PlastSurg, $52(1), 80-88$. 
[23] Boyce, D.E., Jones, W.D., Ruge, F., Harding, K.G., and Moore, K, 2000, Br.J.Dermatol, 143 (1), 59-65.

[24] Hijnen, D., Knol, E.F., Gent, Y.Y., Giovannone, B., Beijn, S., Kupper, T.S., BruijnzeelKoomen, C.A.F.M., and Clark, R.A, 2013, J. Invest. Dermatol, 133 (4), 1-14. 